\title{
Bioinspired Confinement of Upconversion Nanoparticles for Improved Performance in Aqueous Solution
}

\author{
Philipp U. Bastian, ${ }^{\dagger}$ Leixiao Yu, ${ }^{\ddagger}$ Anna López de Guereñu, ${ }^{\dagger}$ Rainer Haag, ${ }^{\ddagger}$ Michael U. Kumke ${ }^{*}{ }^{\dagger}$ \\ 'Institute of Chemistry (Physical Chemistry), University of Potsdam, Potsdam (Golm) 14476, Germany \\ ${ }^{\ddagger}$ Institute of Chemistry and Biochemistry, Freie Universität Berlin, Berlin 14195, Germany
}

Keywords: Upconversion Nanoparticles, RET, UCNP-to-dye-RET, TAMRA, biofunctionalization

Supporting information include additional graphics and illustrations. Figure S1, PL emission spectra of $\mathrm{NaYF}_{4}: \mathrm{Yb}, \mathrm{Er}_{\text {and }} \mathrm{NaYF}_{4}: \mathrm{Yb}, \mathrm{Tm}$ UCNPs after long time storage $\left(\lambda_{\mathrm{ex}}=976 \mathrm{~nm}\right)$; Figure S2, Histograms from TEM evaluation of the $\mathrm{NaYF}_{4}: \mathrm{Yb}, \mathrm{Er}$ UCNPs covered with CMP - same sample from 2017 and 2020; Figure S3, PL emission spectra of the reaction mixture and supernatants of the purification and photo of the dispersions; Figure S4, Fluorescence emission and absorption spectra of TAMRA after the coupling reaction and purification; Figure S5, Low temperature measurement of UCNPझTAMRA, PL emission and kinetics in a temperature range of 4-200 K $\left(\lambda_{\mathrm{ex}}=976 \mathrm{~nm}\right)$; Table S1, detailed PL decay times of the green emission $G 2(540 \mathrm{~nm})$, the red emission R $(654 \mathrm{~nm})$ and the TAMRA emission $(600 \mathrm{~nm})$ peaks excited via RET from NaYF $4: Y b, \operatorname{Er~UCNP}\left(\lambda_{\mathrm{ex}}=976 \mathrm{~nm}\right)$; Figure S6, PL emission spectra of UCNPミTAMRA at low temperatures (4-200 K), non-normalized spectra $\left(\lambda_{\mathrm{ex}}=976 \mathrm{~nm}\right)$. 


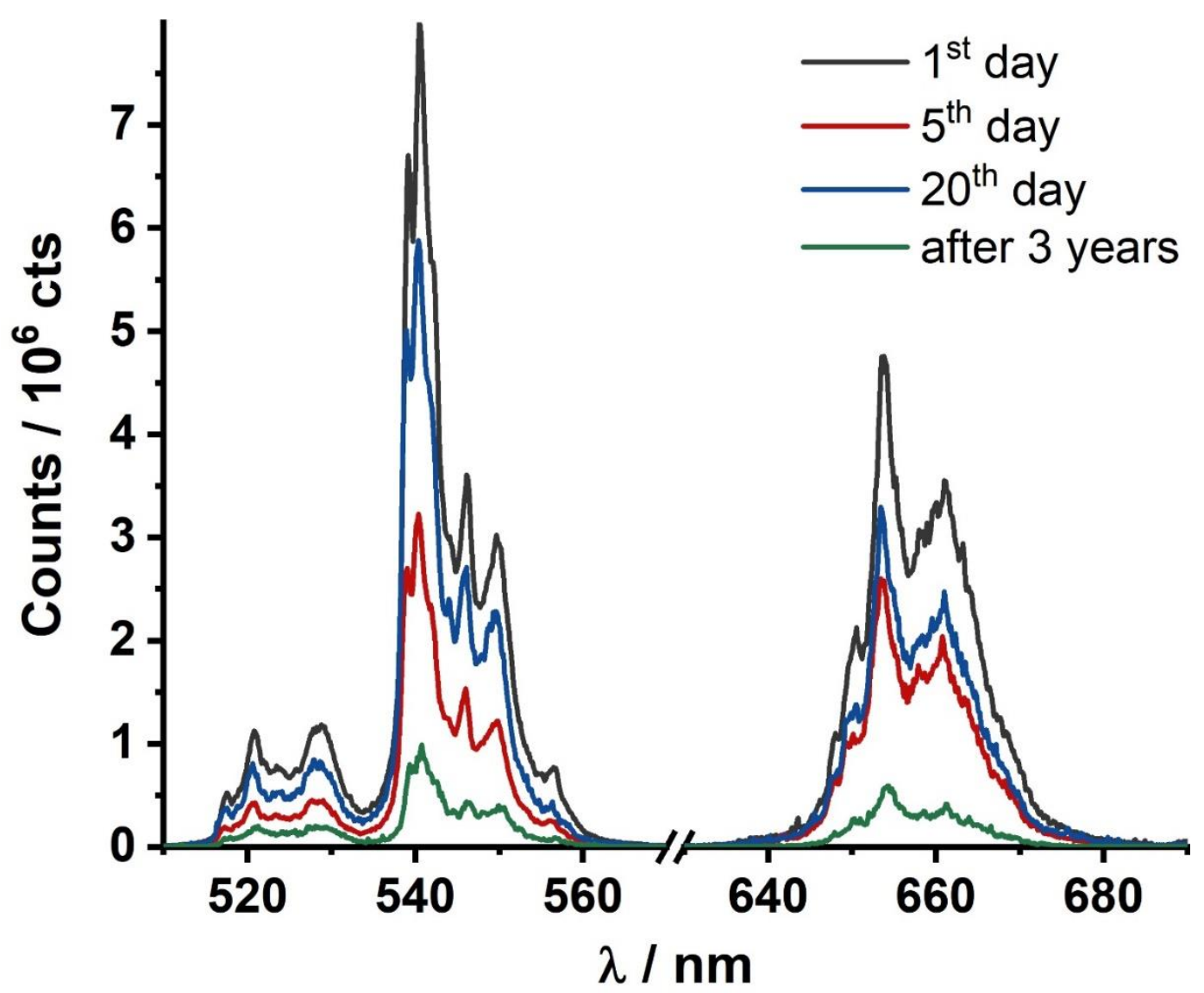

Figure S1. PL emission spectra of $\mathrm{NaYF}_{4}: \mathrm{Yb}, \mathrm{Er}$ UCNP encapsulated in CMP. The total PL emission is shown, the recording settings were almost kept constant but the laser excitation power was not controlled. $\left(\lambda_{\mathrm{ex}}=976 \mathrm{~nm}\right.$; emission from 500-700 nm not measured). Both plots show, that the PL emission intensity decreases moderately over time which can be attributed to the extraordinary properties of CMP described in the corresponding publication. ${ }^{1}$ 

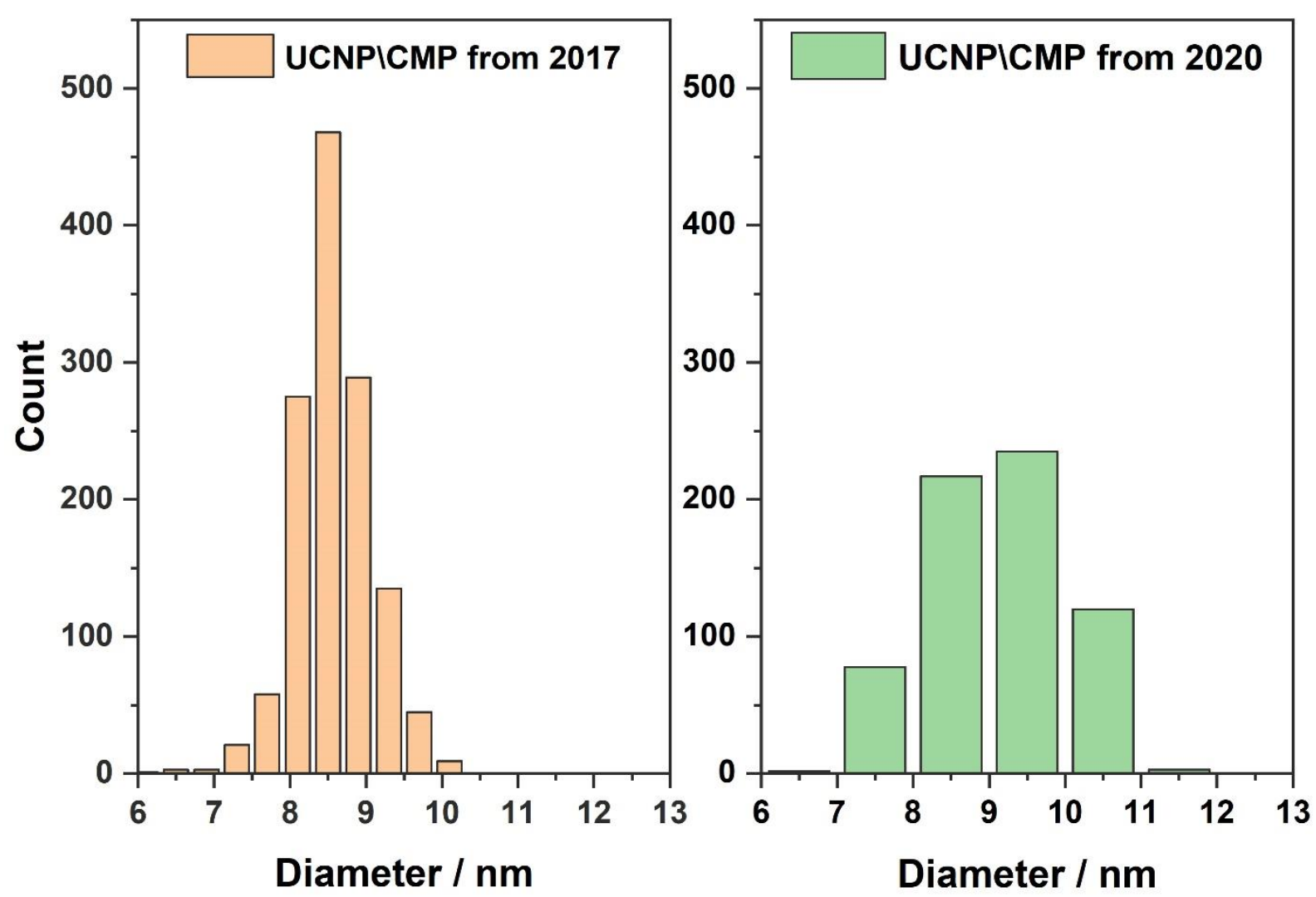

Figure S2. Histograms from TEM size evaluation of the $\mathrm{NaYF}_{4}: \mathrm{Yb}, \mathrm{Er}$ UCNPs covered with CMP. Sample from 2017 and the same sample after storage in a fridge at $(5 \pm 1)^{\circ} \mathrm{C}$ from 2020 is shown.
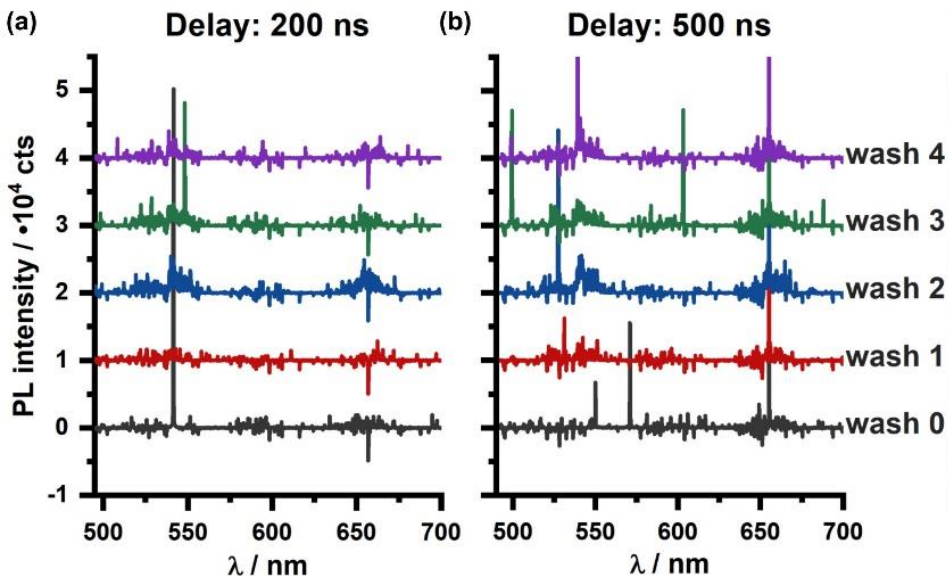

(c)

Figure S3. PL emission spectra of the reaction mixture (wash 0) and the washes 1-4 recorded with (a) $200 \mathrm{~ns}$ and (b) $500 \mathrm{~ns}$ delay time. It demonstrates that TAMRA cannot be excited in the NIR ( $976 \mathrm{~nm}$ ). Some UCNP residues can be identified by its green $\mathrm{G1} \& \mathrm{G} 2$ and red R emission. But, the amount is insufficient to excite the TAMRA via RET.

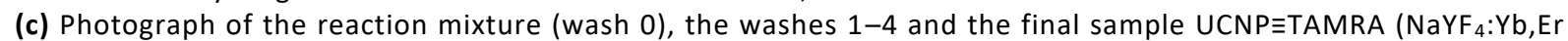
covered with CMP and coupled with TAMRA-5-alkyne). The solvent is water. It shows: The color intensity decreases with each washing step and the sample has higher color intensity than the washes. That means, the final sample contains more TAMRA than the washes. 
It was excluded that TAMRA could be accidentally excited with $976 \mathrm{~nm}$ by testing the supernatants luminescence emission. Furthermore, a concentration decrease with each purification step can be seen in the fluorescence and absorption spectra with a strong hyperchromic effect, ${ }^{2-4}$ which can also be observed by eye. These finding are illustrated in the SI Figure S3 and Figure S4. It is worth to mention that roughly $5 \mathrm{nmol}$ dye are coupled to $30 \mathrm{mg}$ UCNP\CMP so that the TAMRA concentration is roughly $0.16 \mathrm{nmol}$ per mg of UCNP\CMP (based on the absorbance of UCNPミTAMRA at $554 \mathrm{~nm}$ in the SI Figure S4).

(a)
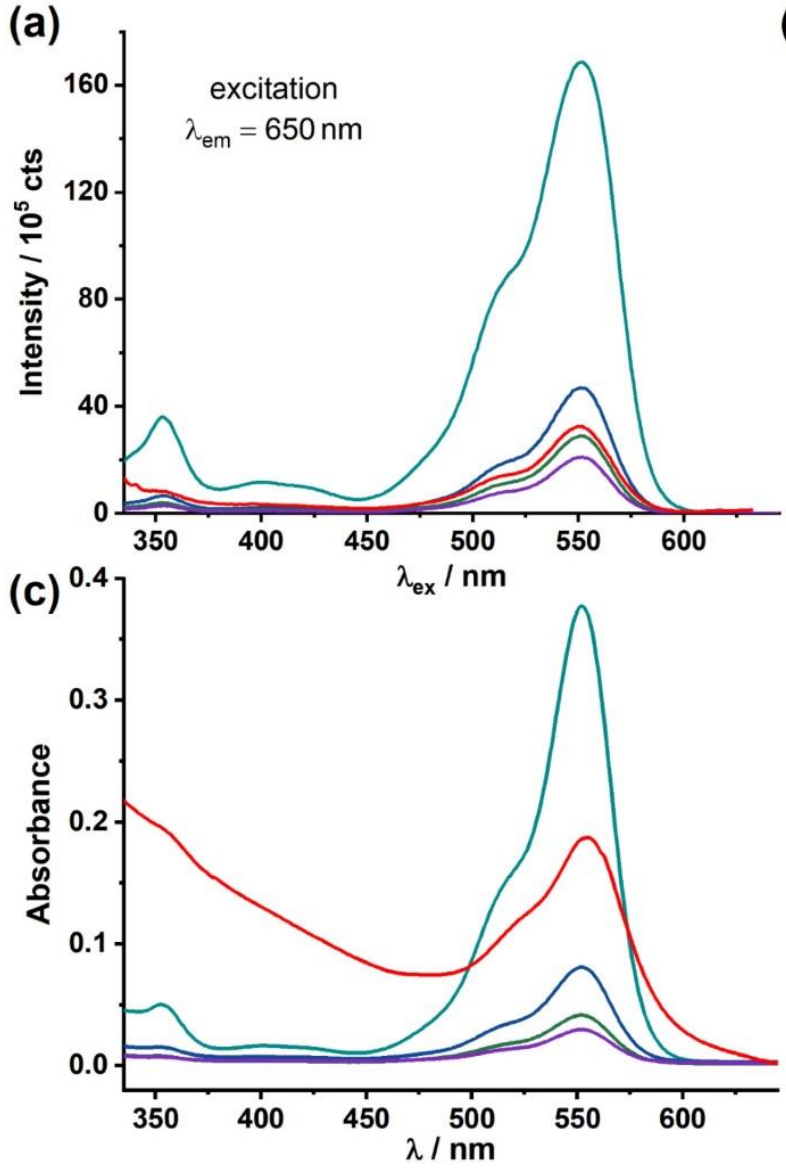

(b)

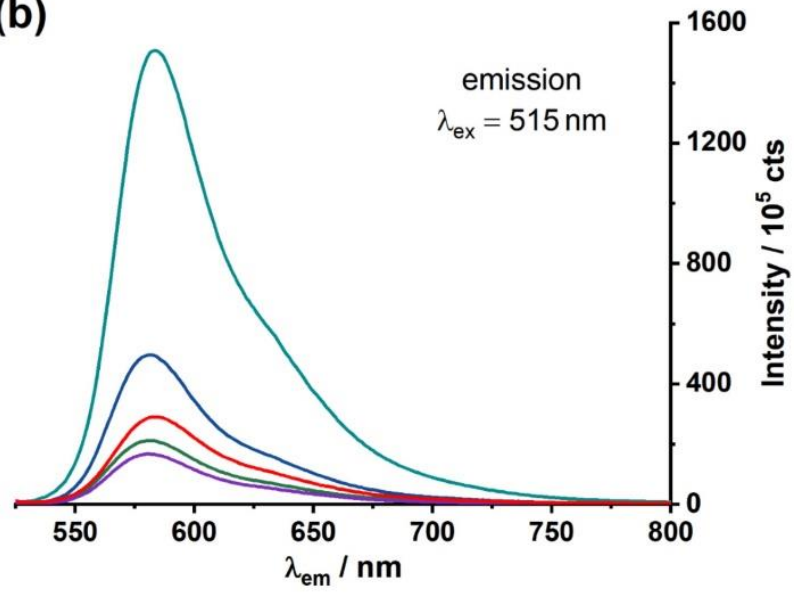

Figure S4: Fluorescence emission and absorption spectra of TAMRA after the coupling reaction. Supernatants from the purification after centrifugation (washes 1-4) and the final product UCNPझTAMRA in water are shown. (a) Steady-state fluorescence excitation spectra with $\lambda_{\mathrm{em}}=650 \mathrm{~nm}$. (b) Steady-state fluorescence emission spectra with $\lambda_{\mathrm{ex}}=515 \mathrm{~nm}$. (c) Absorption spectra. The final sample has higher absorption and higher fluorescence intensity than the last washes. 
Table S1. Detailed PL decay times of the green emission G2 $(540 \mathrm{~nm})$, the red emission R $(654 \mathrm{~nm})$ and the TAMRA emission peak $(600 \mathrm{~nm})$ excited via RET from NaYF 4 :Yb,Er UCNP $\left(\lambda_{\text {ex }}=976 \mathrm{~nm}\right)$. The intensity weighted average PL decay time $\bar{\tau}$ is shown: $\bar{\tau}=\sum f_{j} \tau_{j}$ with $f_{j}=\frac{A_{j} \tau_{j}}{\sum_{i}\left(A_{i} \tau_{i}\right)}$. The amplitude weighted average PL decay time $\langle\tau\rangle=\sum \alpha_{j} \tau_{j}$ with $\alpha_{j}=\frac{A_{j}}{\sum_{i} A_{i}}$. The PL decay time decreases due to phase transfer from cyclohexane (cy) into water. The UCNP PL decay time increases again after click reaction with TAMRA being independent on the dispersion media (water or MOPS buffer with $\mathrm{pH}=6, .1 \mathrm{~mol} / \mathrm{L}$ ).

\begin{tabular}{|c|c|c|c|c|c|c|}
\hline$\lambda_{\mathrm{ex}}$ & $\begin{array}{l}\text { UCNP\OA } \\
\text { in cy }\end{array}$ & $\begin{array}{l}\text { UCNPICMP } \\
\text { in MOPS }\end{array}$ & $\begin{array}{c}\text { UCNPETAMRA } \\
\text { in } \mathrm{H}_{2} \mathrm{O}\end{array}$ & $\begin{array}{c}\text { UCNPETAMRA } \\
\text { in MOPS }\end{array}$ & $\begin{array}{l}\text { UCNPETAMRA } \\
\text { in } \mathrm{H}_{2} \mathrm{O}\end{array}$ & $\begin{array}{c}\text { UCNPETAMRA } \\
\text { in MOPS }\end{array}$ \\
\hline $976 \mathrm{~nm}$ & \multicolumn{4}{|c|}{ Peak = 540 nm (G2) } & \multicolumn{2}{|c|}{ Peak = 600 nm (TAMRA) } \\
\hline$\tau_{1}$ & $59 \mu \mathrm{s}$ & $10 \mu \mathrm{s}$ & $21 \mu \mathrm{s}$ & $26 \mu s$ & $0.01 \mu \mathrm{s}$ & $11 \mu \mathrm{s}$ \\
\hline$\pm \mathrm{ER}\left(\tau_{1}\right)$ & $2 \mu s$ & $1 \mu \mathrm{s}$ & $1 \mu \mathrm{s}$ & $2 \mu s$ & $4 \mu s$ & $3 \mu \mathrm{s}$ \\
\hline$\alpha_{1}$ & $93 \%$ & $82 \%$ & $84 \%$ & $79 \%$ & $0 \%$ & $75 \%$ \\
\hline$f_{1}$ & $82 \%$ & $50 \%$ & $57 \%$ & $52 \%$ & $0 \%$ & $44 \%$ \\
\hline$\tau_{2}$ & $160 \mu \mathrm{s}$ & $37 \mu \mathrm{s}$ & $77 \mu \mathrm{s}$ & $80 \mu \mathrm{s}$ & $17 \mu s$ & $35 \mu \mathrm{s}$ \\
\hline $\pm E R\left(\tau_{2}\right)$ & $17 \mu \mathrm{s}$ & $2 \mu s$ & $4 \mu \mathrm{s}$ & $7 \mu \mathrm{s}$ & $1 \mu \mathrm{s}$ & $8 \mu \mathrm{s}$ \\
\hline$\alpha_{2}$ & $7 \%$ & $17 \%$ & $15 \%$ & $19 \%$ & $91 \%$ & $23 \%$ \\
\hline$f_{2}$ & $18 \%$ & $39 \%$ & $37 \%$ & $38 \%$ & $70 \%$ & $44 \%$ \\
\hline$\tau_{3}$ & $538 \mu \mathrm{s}$ & $126 \mu \mathrm{s}$ & $181 \mu \mathrm{s}$ & $175 \mu \mathrm{s}$ & $74 \mu \mathrm{s}$ & $122 \mu \mathrm{s}$ \\
\hline $\pm E R\left(\tau_{3}\right)$ & $755 \mu \mathrm{s}$ & $4 \mu \mathrm{s}$ & $14 \mu \mathrm{s}$ & $15 \mu \mathrm{s}$ & $3 \mu \mathrm{s}$ & $28 \mu \mathrm{s}$ \\
\hline$\alpha_{3}$ & $0.05 \%$ & $2 \%$ & $1 \%$ & $2 \%$ & $9 \%$ & $2 \%$ \\
\hline$f_{3}$ & $0.04 \%$ & $12 \%$ & $6 \%$ & $10 \%$ & $30 \%$ & $12 \%$ \\
\hline $\bar{\tau}$ & $79 \mu \mathrm{s}$ & $34 \mu \mathrm{s}$ & $52 \mu \mathrm{s}$ & $62 \mu \mathrm{s}$ & $34 \mu s$ & $35 \mu \mathrm{s}$ \\
\hline teR $(\bar{\tau})$ & $2 \mu s$ & $1 \mu \mathrm{s}$ & $1 \mu \mathrm{s}$ & $1 \mu \mathrm{s}$ & $0.6 \mu \mathrm{s}$ & $2 \mu \mathrm{s}$ \\
\hline$\langle\tau\rangle$ & $67 \mu \mathrm{s}$ & $16 \mu \mathrm{s}$ & $32 \mu \mathrm{s}$ & $40 \mu \mathrm{s}$ & $22 \mu \mathrm{s}$ & $18 \mu \mathrm{s}$ \\
\hline $\operatorname{\pm ER}(\langle\tau\rangle)$ & $1 \mu \mathrm{s}$ & $1 \mu \mathrm{s}$ & $1 \mu s$ & $1 \mu \mathrm{s}$ & $1 \mu s$ & $2 \mu \mathrm{s}$ \\
\hline 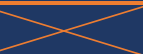 & 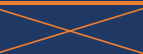 & $<$ & $>$ & $<$ & & \\
\hline$\lambda_{\text {ex }}$ & $\begin{array}{l}\text { UCNP } \backslash O A \\
\text { in cy }\end{array}$ & $\begin{array}{l}\text { UCNPICMP } \\
\text { in MOPS }\end{array}$ & $\begin{array}{l}\text { UCNP } \equiv \text { TAMRA } \\
\text { in } \mathrm{H}_{2} \mathrm{O}\end{array}$ & $\begin{array}{l}\text { UCNPETAMRA } \\
\text { in MOPS }\end{array}$ & & \\
\hline $976 \mathrm{~nm}$ & \multicolumn{4}{|c|}{ Peak = $654 \mathrm{~nm}(\mathrm{R})$} & & \\
\hline$\tau_{1}$ & $0 \mu s$ & $27 \mu \mathrm{s}$ & $37 \mu s$ & $34 \mu s$ & & \\
\hline $\pm E R\left(\tau_{1}\right)$ & $0 \mu \mathrm{s}$ & $2 \mu \mathrm{s}$ & $2 \mu \mathrm{s}$ & $2 \mu \mathrm{s}$ & & \\
\hline$\alpha_{1}$ & $0 \%$ & $84 \%$ & $87 \%$ & $89 \%$ & & \\
\hline$f_{1}$ & $0 \%$ & $56 \%$ & $54 \%$ & $56 \%$ & & \\
\hline$\tau_{2}$ & $90 \mu \mathrm{s}$ & $73 \mu \mathrm{s}$ & $142 \mu \mathrm{s}$ & $147 \mu \mathrm{s}$ & & \\
\hline $\pm E R\left(\tau_{2}\right)$ & $3 \mu \mathrm{s}$ & $7 \mu \mathrm{s}$ & $38 \mu \mathrm{s}$ & $27 \mu \mathrm{s}$ & & \\
\hline$\alpha_{2}$ & $78 \%$ & $13 \%$ & $7 \%$ & $6 \%$ & & \\
\hline$f_{2}$ & $49 \%$ & $24 \%$ & $18 \%$ & $17 \%$ & & \\
\hline$\tau_{3}$ & $325 \mu \mathrm{s}$ & $309 \mu \mathrm{s}$ & $316 \mu \mathrm{s}$ & $328 \mu \mathrm{s}$ & & \\
\hline$\pm \mathrm{ER}\left(\tau_{3}\right)$ & $7 \mu s$ & $7 \mu \mathrm{s}$ & $25 \mu \mathrm{s}$ & $16 \mu \mathrm{s}$ & & \\
\hline$\alpha_{3}$ & $22 \%$ & $3 \%$ & $5 \%$ & $4 \%$ & & \\
\hline$f_{3}$ & $51 \%$ & $21 \%$ & $28 \%$ & $26 \%$ & & \\
\hline $\bar{\tau}$ & $209 \mu s$ & $97 \mu s$ & $133 \mu \mathrm{s}$ & $131 \mu s$ & & \\
\hline $\pm E R(\bar{\tau})$ & $2 \mu \mathrm{s}$ & $1 \mu \mathrm{s}$ & $2 \mu s$ & $2 \mu \mathrm{s}$ & & \\
\hline$\langle\tau\rangle$ & $142 \mu s$ & $41 \mu \mathrm{s}$ & $60 \mu \mathrm{s}$ & $54 \mu s$ & & \\
\hline $\pm E R(\langle\tau\rangle)$ & $2 \mu \mathrm{s}$ & $1 \mu s$ & $1 \mu s$ & $2 \mu s$ & & \\
\hline
\end{tabular}



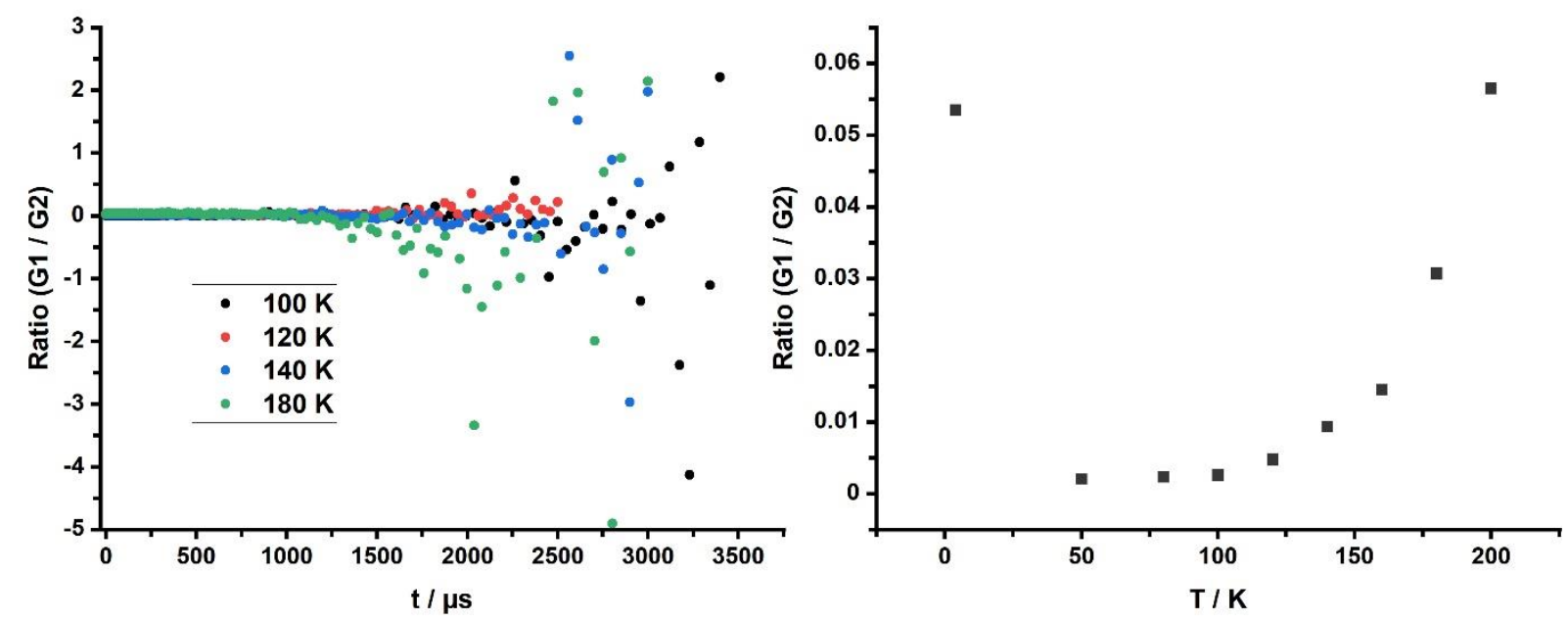

Figure S5. Low temperature measurements of UCNPミTAMRA. PL emission and kinetic investigations, $\lambda_{\mathrm{ex}}=976 \mathrm{~nm}$. Left: Ratios of G1/G2 emission from kinetic measurements. The time dependent ratios are constant. Only $140 \mathrm{~K}$ and $180 \mathrm{~K}$ show deviations, upwards and downwards, respectively. Right: Ratios of G1/G2 emission from emission measurements. They show clearly that the G1 emission increases in intensity with increasing temperature. The exemption for the $4 \mathrm{~K}$ ratio, whose total intensity emission is very low, correlates with very little G2 emission. G1 emission cannot be detected below $100 \mathrm{~K}$.

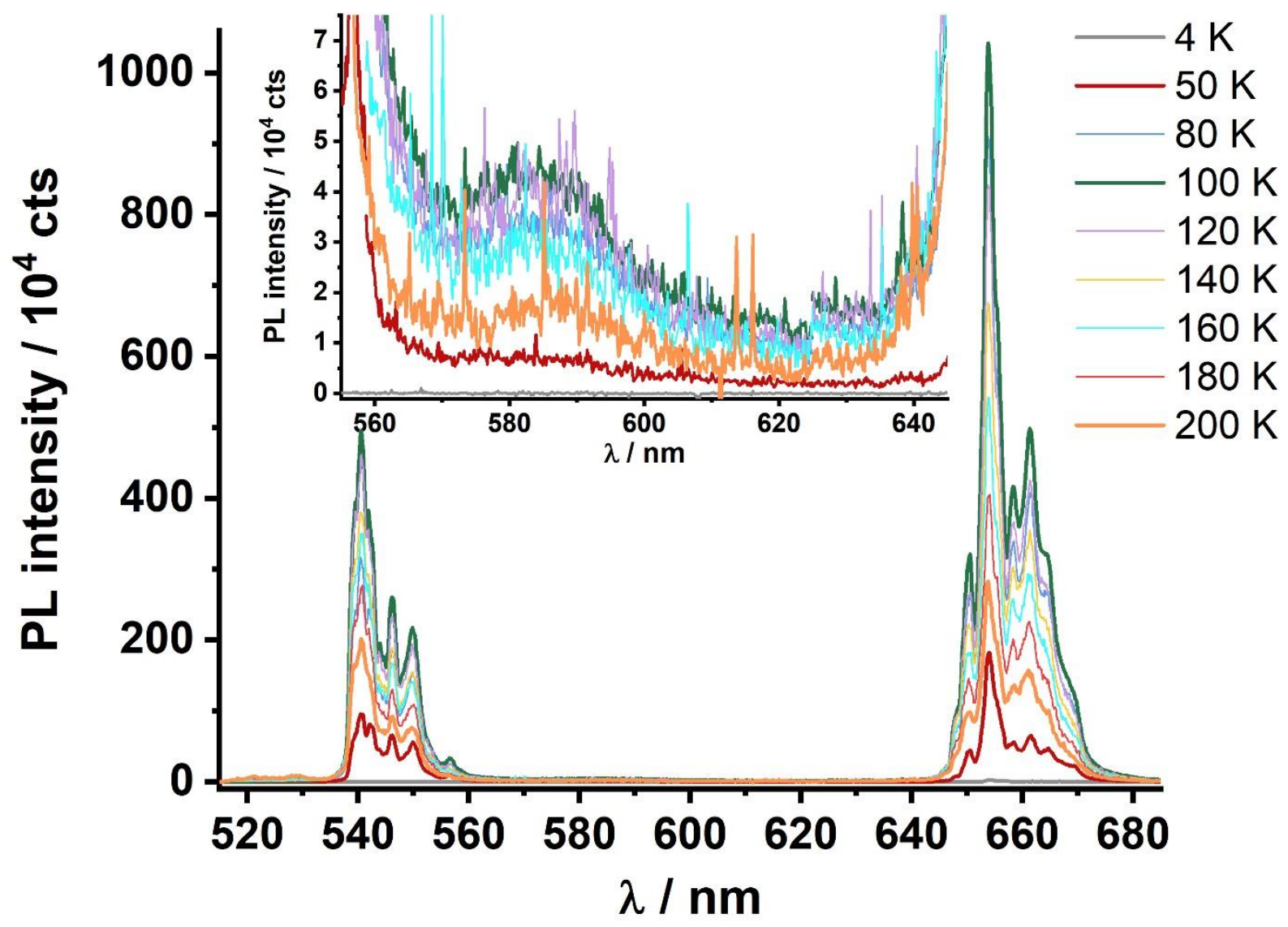

Figure S6. PL emission spectra of UCNP $\equiv T A M R A$ at low temperatures with $\mathrm{T}$ in $\mathrm{K}$. The PL emission intensities increase with increasing temperature up to $100 \mathrm{~K}$ - accounting for all emission bands of G1 (520 nm), G2 (540 nm), TAMRA $(585 \mathrm{~nm})$ and $\mathrm{R}(654 \mathrm{~nm})$. When T exceeds $100 \mathrm{~K}$ the PL emission intensities decrease with T increasing, which could relate to stronger pronounced multiphonon relaxation processes. 


\section{References}

(1) Yu, L.; Cheng, C.; Ran, Q.; Schlaich, C.; Noeske, P.-L. M.; Li, W.; Wei, Q.; Haag, R. Bioinspired Universal Monolayer Coatings by Combining Concepts from Blood Protein Adsorption and Mussel Adhesion. ACS Appl. Mater. Interfaces 2017, 9, 6624-6633.

(2) Sabaté, R.; Freire, L.; Estelrich, J. Influence of Dielectric Constant on the Spectral Behavior of Pinacyanol. A Spectrophotometric Experiment for Physical Chemistry. J. Chem. Educ. 2001, 78, 243.

(3) Ackerman, M. M.; Ricciardi, C.; Weiss, D.; Chant, A.; Kraemer-Chant, C. M. Analyzing Exonuclease-Induced Hyperchromicity by UV Spectroscopy: An Undergraduate Biochemistry Laboratory Experiment. J. Chem. Educ. 2016, 93, 2089-2095.

(4) Winter, R.; Noll, F.; Czeslik, C. Methoden der Biophysikalischen Chemie; Vieweg+Teubner Verlag, Springer Fachmedien Wiesbaden, 2011. 